\title{
Advances in the Study of Acute Acalculous Cholecystitis: A Comprehensive Review
}

\author{
Yantao $\mathrm{Fu}^{\mathrm{a}}$ Liwei Pang ${ }^{\mathrm{a}}$ Wanlin Dai ${ }^{\mathrm{b}}$ Shuodong $\mathrm{Wu}^{\mathrm{a}}$ Jing Kong \\ aDepartment of General Surgery, Shengjing Hospital of China Medical University, Shenyang, China; \\ bInnovation Institute of China Medical University, Shenyang, China
}

\section{Keywords}

Acute acalculous cholecystitis · Ischemia-reperfusion injury · Critical illness · Decompression treatment

\begin{abstract}
Background: Acute acalculous cholecystitis (AAC) is characterized by acute necrotizing inflammation with no calculi and is diagnosed based on imaging, intraoperative, and pathological examinations. Key Message: Although AAC has been studied clinically for a long time, it remains difficult to diagnose and treat. The pathogenesis of AAC is still not fully understood, and it is often regarded as a relatively independent clinical disease that is different from acute calculous cholecystitis (ACC). Pathological studies suggest that $A A C$ is the manifestation of a critical systemic disease, while ACC is a local disease of the gallbladder. Summary: Concerning the pathogenesis, diagnosis, and treatment of $A A C$, we reviewed the research progress of $A A C$, which will enhance the understanding of the early diagnosis and treatment of AAC.
\end{abstract}

(c) 2021 S. Karger AG, Basel

\section{Introduction}

Acute acalculous cholecystitis (AAC) can be defined as an acute inflammatory disease of the gallbladder without the evidence of gallstones. Acute cholecystitis accounts for $3-10 \%$ of all cases of abdominal pain; it is found to be lower $(6.3 \%)$ in patients $<50$ years of age and higher (20.9\%) average, $10 \%)$ in patients $\geq 50$ years of age. Cholecystolithiasis accounts for $90-95 \%$ of all causes of acute cholecystitis, while acalculous cholecystitis accounts for the remaining 5-10\% [1]. The clinical manifestations of AAC are atypical and include complex etiology, rapid onset, and rapid disease progression. A diagnosis of AAC can be made based on clinical features including right upper abdominal pain, positive Murphy's sign, and fever, regardless of negative laboratory or imaging findings [2, $3]$. The pathogenesis of AAC is complex and multifactorial, including anatomical and functional factors, and can cause gallbladder ischemia, bile excretion disorder, cholestasis, and secondary bacterial infection. Anatomical abnormalities of the biliary system are common in children with acute cholecystitis [4]. AAC often occurs postoperatively in trauma centers and intensive care units. It is often found in critically ill patients, such as patients in coma, those undergoing endotracheal intubation, using sedative and analgesic drugs, unable to communicate verbally, or to cooperate with physical examinations, or those covered by primary diseases [5]. Clinical symptoms, laboratory results, and imaging modalities, such as B-scan ultrasound, computed tomography (CT), magnetic resonance cholangiopancreatography (MRCP), and hepatobiliary dynamic imaging, are significant diagnostic methods. Owing to the rapid onset and disease progres- karger@karger.com

www.karger.com/ddi (c) 2021 S. Karger AG, Basel

Karger!
Correspondence to:

Jing Kong, kongjing1998@163.com 
sion of AAC, it is necessary to intervene as soon as possible after diagnosis. Current treatments include conservative treatment, cholecystectomy, percutaneous cholecystostomy (PC), and placement of a lumen-apposing fully covered metal stent (LAMS). However, treatment is usually personalized and based on age, severity of the disease, complications, and tolerance to surgery [5]. The purpose of this manuscript is to present the current state of knowledge regarding the pathogenesis, diagnosis, and treatment of AAC.

\section{Types of AAC}

Pathologically, AAC is divided into simple cholecystitis, acute suppurative cholecystitis, gangrene cholecystitis, and gallbladder perforation. Based on the etiology, the inflammation associated with AAC can be classified as mechanical (due to increase in cystic cavity pressure, leading to compression and ischemia of the gallbladder wall and mucosa), chemical (the activity of phospholipases on the lecithin of bile produces hemolytic lecithin, which then causes chemical inflammation), or bacterial (caused by Escherichia coli, Klebsiella bacillus, Streptococcus spp, and Staphylococcus aureus present in the gallbladder).

\section{Pathogenesis of AAC}

Gallbladder Ischemia-Reperfusion Injury

Ischemia-reperfusion injury plays a major role in the pathogenesis of AAC. Because the gallbladder artery is terminal artery, ischemic necrosis of the gallbladder wall is common with insufficient blood supply [6]. Stress (related to surgery or trauma), hypotension, and vasoactive drug use may cause vasoconstriction, resulting in insufficient perfusion. On the other hand, cholestasis will increase the pressure within the gallbladder cavity, thus decreasing perfusion to the gallbladder wall. Orlando et al. [7] studied 9 patients and theorized that gallbladder ischemia and cholestasis lead to under perfusion. They believed that reperfusion injury may be the key factor, while bacterial invasion, the secondary factor. Long-term ischemia leads to activation of phospholipase A2 and superoxide dismutase, as well as increase in the content of lipid peroxides, which can also directly lead to damage and necrosis of the gallbladder mucosa [8]. Hakala et al. [9] used microangiography in 10 patients to show that there was a significant difference between acute calculous cholecystitis (ACC) and AAC. AAC angiography showed obvious arterial dilatation and normal capillary filling. Therefore, they suggested that AAC should be renamed as acute isch- emic cholecystitis because it provides a better explanation of the etiology, pathogenesis, and other characteristics of $\mathrm{AAC}$, which further classify it as a relatively independent clinical disease. Vakkala et al. [10] also conducted a controlled study including 39 AAC patients and 30 ACC patients; they confirmed the correlation between ischemiareperfusion injury of the gallbladder and inflammatory mediators. Histopathological analyses revealed that neutrophils, mononuclear inflammatory cells, and eosinophilic granulocytes are less present in AAC compared to ACC. The authors also conducted an immunohistochemical analysis and demonstrated that cell proliferation and apoptosis are increased in AAC, while intense expression of hypoxia-inducible factor-1 alpha is associated with increased cell proliferation. Other studies have also shown that the hypoperfusion of body organs caused by cardiovascular disease and certain medical conditions can lead to gallbladder ischemia-reperfusion injury [11].

\section{Cholestasis}

Long-term fasting, parenteral nutrition, intestinal obstruction, and severe dehydration caused by burns and trauma can lead to functional bile excretion disorders. Intraoperative and postoperative administration of sedatives and analgesics (such as morphine) can also affect the contraction of the gallbladder and the function of the sphincter of Oddi, which can further cause cholestasis $[12,13]$. Additionally, previous studies have reported that hormones (estrogen and progesterone) and certain drugs (i.e., oral contraceptives, thiazides, ceftriaxone, octreotide, erythromycin, ampicillin, sunitinib, sorafenib, and alemtuzumab) inhibit diastole and contraction of the gallbladder smooth muscle, which causes cholestasis [1416]. Abnormal lipid metabolism, caused by type II diabetes and cerebrovascular disease, increases the bile viscosity, which could also lead to cholestasis [11]. Finally, the metabolites of viruses and parasites, such as Epstein-Barr virus, hepatitis A virus, hepatitis E virus, Clonorchis sinensis, giardia, and Echinococcus species, may invade the wall of the gallbladder or biliary epithelial cells, leading to cholestasis [17-22]. Cholestasis and bile concentration can lead to changes in the chemical composition of bile; a high concentration of bile salt can stimulate the mucus membrane of the gallbladder, causing damage and increasing the risk of perforation and gallbladder gangrene [23].

\section{Bacterial Infections}

Bacteria are not normally present in the bile. Bacterial invasion mainly leads to biliary retrograde infection and 


\begin{tabular}{ll}
\hline $\begin{array}{l}\text { Diabetes mellitus } \\
\text { Arterial hypertension } \\
\text { Atherosclerosis } \\
\text { Vasculitis }\end{array}$ \\
$\begin{array}{l}\text { Stroke } \\
\text { Immunodeficiency }\end{array}$ \\
$\begin{array}{l}\text { Systemic lupus erythematosus, macrophage } \\
\text { activation syndrome, and acquired } \\
\text { immunodeficiency syndrome }\end{array}$ \\
$\begin{array}{l}\text { Lymphokine-activated killer cell therapy } \\
\text { Components of bile }\end{array}$ & $\begin{array}{l}\text { Hemolytic phosphatidylcholine and } \\
\text { glucuronidase }\end{array}$ \\
Neural factors & \\
\hline
\end{tabular}

AAC, acute acalculous cholecystitis. is caused mostly by Gram-negative bacteria (such as $E$. coli, K. bacillus, Salmonella spp, Brucellosis, Vibrio cholerae, and Leptospira) and few Gram-positive bacteria (such as Enterococcus faecalis, and Staphylococcus Fusarium spp, and Lactococcus spp) [24-28]. Notably, a case of ehrlichiosis has been reported with a manifestation of AAC [29]. Because of the normal structure and function of the sphincter of Oddi, intestinal bacteria generally cannot pass easily into the biliary system to cause infection. Inappropriate use of opioid analgesics during gastrointestinal surgeries, injury, and spasms of the sphincter of Oddi can increase the risk of infection. Furthermore, endoscopic retrograde cholangiopancreatography (ERCP) may pose a risk for bacterial infection, owing to its invasiveness [30]. Systemic infection caused by sepsis can also cause AAC, especially when bacteria colonizes the gallbladder via the circulation of blood. Moreover, infections in the surrounding organs can directly transfer bacteria to the gallbladder, thus inducing AAC.

Abnormal Anatomical Structure of the Biliary Tract System

Acute cholecystitis in children is always considered to be acalculous cholecystitis [4]. A congenital developmental disorder of the biliary tract causes bile emptying disorder due to factors such as an extended gallbladder neck, gallbladder torsion, biliary cysts, and stenosis of the pipe diameter [4]. The gallbladder has motor functions, with 20-30\% emptying at 1- to 2-h intervals during the fasting state and $70-80 \%$ emptying after stimulation by cholecystokinin during food intake [31]. The interplay between gallbladder contraction and relaxation has a vital role in driving bile salts into enterohepatic circulation to facili- tate the absorption of lipids and fat-soluble vitamins [3133]. Thus, weakened gallbladder motility leads to bile retention, which can increase the risk of AAC [31-33]. Moreover, Falk et al. [34] reported a patient with Mirizzi syndrome, who was intraoperatively found to have a complete intrahepatic gallbladder, causing common hepatic duct compression.

\section{Other Risk Factors}

Associated factors such as diabetes mellitus, arterial hypertension, atherosclerosis, vasculitis, stroke, and immunodeficiencies (such as systemic lupus erythematosus, macrophage activation syndrome, and acquired immunodeficiency syndrome) may increase the risk of AAC [35-39]. Kullmann et al. [6] showed that neural factors may also induce AAC; in other words, any factor that reduces vagal tone may lead to the occurrence of AAC or may be a contributing factor in the onset of cholecystitis. Individual cases of AAC have been observed in patients who have undergone interleukin-2 therapy, lymphokineactivated killer cell therapy, and bone marrow transplantation [40]. In addition to a high concentration of bile salts, other components of bile, such as hemolytic phosphatidylcholine and glucuronidase, are also associated with the development of AAC (Table 1). Figure 1 demonstrates the complex pathogenesis of AAC.

\section{Diagnosis}

Signs and Symptoms

Patients may present with persistent or intermittent right upper abdominal pain and unexplained fever, which are generally accompanied by nonspecific signs of gastrointestinal diseases, such as nausea, vomiting, and jaun- 


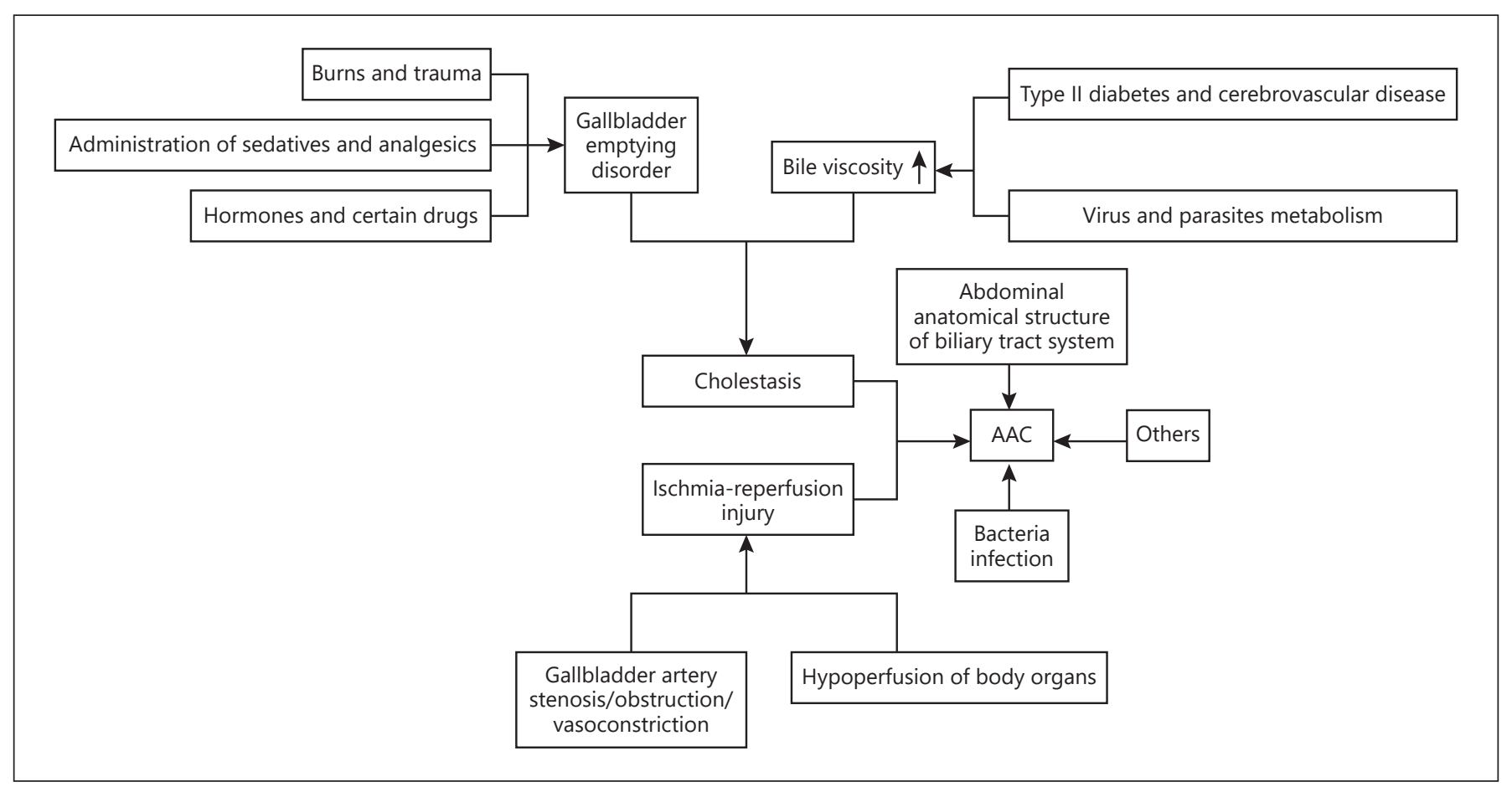

Fig. 1. The pathogenesis of AAC. AAC, acute acalculous cholecystitis.

dice. Signs of gallbladder perforation include right epigastric tenderness, palpable right epigastric mass, a positive Murphy's sign (+), and peritoneal irritation (total abdominal tenderness, rebound pain, and muscle tension) [41].

\section{Laboratory Investigations}

When patients develop AAC, the following laboratory abnormalities may occur: white blood cell, neutrophils, and C-reactive protein levels may be higher than normal; increase in aminotransferase may be noted, which may be accompanied by mild-to-moderate increases in the bilirubin level; slight elevation of blood amylase, with the exclusion of other factors related to elevated amylase; diagnostic abdominal perforation, or bile-like fluid extraction; and positive blood cultures. However, these clinical manifestations and laboratory indicators are nonspecific, and the interference of other related diseases can only be used as a reference for the diagnosis of AAC [41].

\section{Imaging}

When patients, especially gerontal patients, show the above clinical manifestations, abnormal laboratory indicators, and signs of acute or severe disease or chronic wasting, AAC should be considered. Imaging often aids in the diagnosis of AAC. B-scan ultrasonic examination is considered a simple and effective method and can be conducted by the bedside. It is often the first-line imaging modality used to diagnose AAC [42]. The diagnostic criteria are as follows: (1) positive ultrasonic Murphy's sign (pressure applied, using the probe, on the gallbladder area causes pain), (2) no stone in the gallbladder (no strong echo group, rear accompanied by an acoustic shadow, and sound image moving with posture), (3) gallbladder enlargement (length diameter $\geq 8 \mathrm{~cm}$ and transverse diameter $\geq 5 \mathrm{~cm}$ ), (4) thickening of the gallbladder wall (gallbladder wall $\geq 3.5 \mathrm{~mm}$, presenting as a "bilateral" or "double-wall" sign), (5) B-scan ultrasound indicating the presence of peritoneal effusion and extraction of bile-like fluid, (6) echo occurring in the gallbladder cavity or wall, and (7) bile (bile sludge is possible) [42]. The specificity ranges between $30 \%$ and $100 \%$; the sensitivity also ranges between $30 \%$ and $100 \%$. Fluctuations occur mainly because of its strong subjectivity, differences in diagnostic criteria, and abdominal intestinal gas interference [43]. A typical ultrasound image is shown in Figure 2.

Abdominal gas does not interfere with $\mathrm{CT}$ examinations. The examination results can be used to rule out other differential diagnoses of abdominal diseases. In patients with suspected AAC, with negative B-scan ultra- 


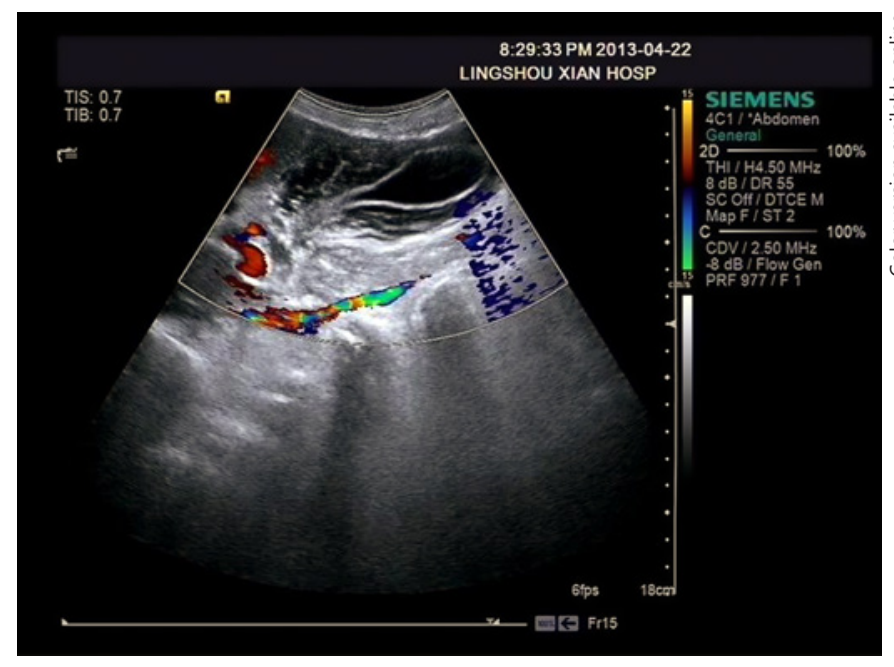

Fig. 2. The ultrasound image shows thickened gallbladder wall and no stones.

sound results, CT can be used to confirm the diagnosis. Therefore, B-scan ultrasound and CT examinations are necessary for improved sensitivity and specificity $[44,45]$. The diagnostic criteria are as follows: (1) no stones in the gallbladder neck or cystic duct and thickened $(\geq 0.3 \mathrm{~cm})$ and enhancing wall; (2) pericholecystic fat stranding with or without pericholecystic fluid and reactive enhancement in the adjacent liver; (3) when gangrenous cholecystitis occurs, nonenhancing wall, sloughed membranes, mural striation, irregular enhancing wall with defect, and pericholecystic fat stranding and fluid are noted (more than that is seen in uncomplicated cholecystitis); and (4) when the gallbladder is perforated, focal defect can be seen in the gallbladder wall along with contiguous pericholecystic fluid or hepatic abscesses [43]. A typical CT image is shown in Figure 3.

MRCP uses magnetic resonance hydrography principles, without a contrast agent. This allows imaging of the bile pancreatic duct system and is simple, noninvasive, and safe. Furthermore, the 3-dimensional, multi-angle biliary imaging can provide an important clinical basis for the diagnosis of AAC, due to the abnormal anatomy of the biliary tree. Shiryajev et al. [46] also reported a case of Mirizzi syndrome complicated with AAC and diagnosed using MRCP. Although ERCP can be used to diagnose and treat $\mathrm{AAC}$, it is more invasive and challenging, compared with MRCP, and is more associated with pancreatitis. For patients with biliary anatomical abnormalities undergoing gastroduodenal surgery, ERCP often has limitations.

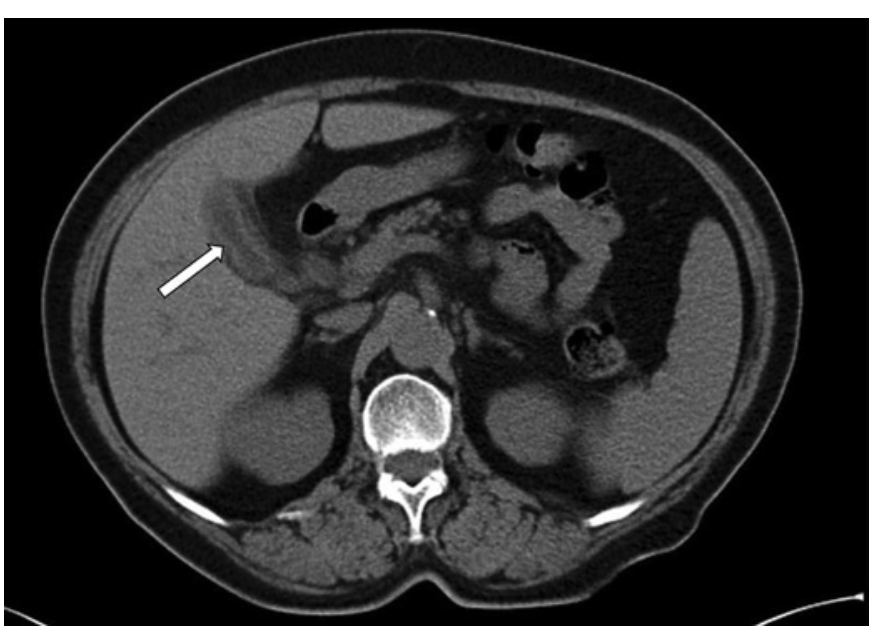

Fig. 3. The axial CT image shows poor enhancement of the gallbladder wall (white arrow), which indicates inflammation of the gallbladder. No gallstone or definite cholecystic fat stranding was identified. CT, computed tomography.

Hepatobiliary dynamic imaging stimulates the liver bilirubin intake process via the intravenous injection of acetanilide iminodiacetic acid compounds, which are marked by imaging agent 99 (99m TC-EHIDA). The imaging agent 99 is a radiopharmaceutical that can be absorbed by liver cells and excreted by the biliary tract. It is secreted into the bile, then excreted in the intestinal tract, and can be observed via a flashing dynamic imaging camera to understand the morphological structure and function of the liver and gallbladder. Under normal circumstances, the gallbladder, common bile duct, and small intestine are all detected within $60 \mathrm{~min}$. According to previous studies, if the gallbladder is not detected within $60 \mathrm{~min}$, the patient is considered AAC positive [47]. Shafiq et al. [47] reported a case of confirmed AAC where the abdominal ultrasound and CT scan were both negative, while the intravenous iminodiacetic acid hepatobiliary (HIDA) scan was positive. HIDA has a specificity ranging from $38 \%$ to $100 \%$ and sensitivity ranging from $67 \%$ to $100 \%$. Any abnormality that can affect the uptake, secretion, and excretion of the imaging agent (such as prolonged fasting, parenteral nutrition treatment, and severe liver disease) may cause no gallbladder development for $60 \mathrm{~min}$, which would result in a false-positive diagnosis. Thus, the HIDA scan is not appropriate for critically ill patients since the examination can last several hours. Morphine can be injected to make the sphincter of Oddi contract, and this may reduce the rate of false-positive results. At the same time, the false-negative rate of HIDA 
Fig. 4. The pathological specimen shows yellow-green mucus membrane in the neck of gallbladder. The gallbladder wall was thickened and hard, and a large number of acute and chronic inflammatory cells were infiltrated, and necrotic and focal glandular hyperplasia were noted in the gallbladder wall.

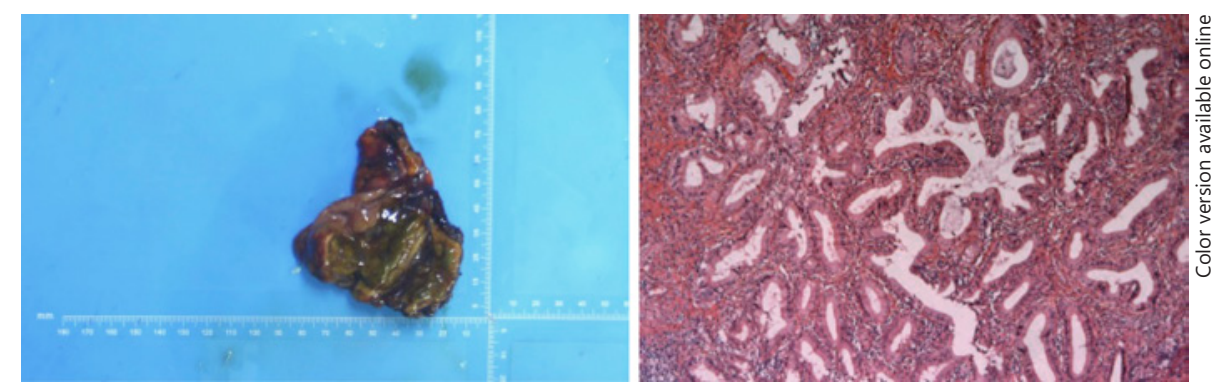

Table 2. Classification of AAC treatments, according to the 2018 Tokyo Guidelines

\begin{tabular}{|c|c|c|}
\hline AAC & Can withstand surgery & Cannot withstand surgery \\
\hline Grade I & Lap-C should ideally be performed & $\begin{array}{l}\text { Conservative treatment should be instituted first; then surgery may } \\
\text { be considered once treatment is seen to take effect }\end{array}$ \\
\hline Grade II & $\begin{array}{l}\text { Lap-C should ideally be performed in an advanced surgical center, } \\
\text { while considering switching to open or subtotal cholecystectomy }\end{array}$ & Conservative treatment and biliary drainage should be considered \\
\hline Grade III & $\begin{array}{l}\text { Early Lap-C can be performed by a specialist surgeon with extensive } \\
\text { experience, in a setting that allows for intensive care management }\end{array}$ & $\begin{array}{l}\text { Conservative treatment, including comprehensive management, } \\
\text { should be instituted. Early biliary drainage should be considered if it } \\
\text { is not possible to control the gallbladder inflammation }\end{array}$ \\
\hline
\end{tabular}

AAC, acute acalculous cholecystitis.

is extremely low, accounting for about $1 \%$, which is visible in gallbladder leakage caused by gallbladder perforation. HIDA is an important examination tool for diagnosing AAC. However, for patients with cystic duct or gallbladder neck obstruction, HIDA is not useful in differentiating between AAC and ACC.

Pathology

Unlike calculous cholecystitis, acalculous cholecystitis mainly results in necrosis of the gallbladder tissue, due to blood circulation disorder. When the circulatory disorder peaks and blood stasis occurs, there is resulting tissue necrosis and bleeding. The mucosal epithelium of the gallbladder wall is degenerated and necrotic, forming multiple erosive ulcers, with numerous neutrophils and other inflammatory cells [48]. Figure 4 shows a pathological specimen of AAC from our hospital.

\section{Therapy}

According to the 2018 Tokyo Guidelines, an effective treatment strategy, which is based on the grade of severity, is selected by assessing risk factors, such as predictive factors, the Charlson Comorbidity Index score, and the American Society of Anesthesiologists-physical status score. Specific criteria for selecting treatment are shown in Table 2 [49]. Grade III (severe) AAC is associated with dysfunction of the organs or systems, including cardiovascular dysfunction, neurological dysfunction, respiratory dysfunction $(\mathrm{PaO} 2 / \mathrm{FiO} 2$ ratio $<300)$, renal dysfunction (oliguria or creatinine $>2.0 \mathrm{mg} / \mathrm{dL}$ ), hepatic dysfunction (PT-INR > 1.5), and hematological dysfunction (platelet count $<100,000 / \mathrm{mm}^{3}$ ). Grade II (moderate) AAC is associated with conditions including elevated WBC count $\left(>18,000 / \mathrm{mm}^{3}\right)$, palpable tender mass in the right upper abdominal quadrant, duration of symptoms $>72 \mathrm{~h}$, and marked local inflammation (gangrenous cholecystitis, pericholecystic abscess, hepatic abscess, biliary peritonitis, and emphysematous cholecystitis). Grade I (mild) AAC can be defined as acute cholecystitis in a healthy patient with no organ dysfunction and mild inflammatory changes in the gallbladder [50]. Patients with AAC have poor systemic conditions; thus, the treatment should focus on improving systemic symptoms. Conservative treatment is recommended for mild AAC in the early stage. Recurrence rate after nonsurgical treatment has been shown to be significantly lower in AAC than in ACC (2.7 vs. $23.2 \%)$ [51-53]. Moreover, surgical treatment is recommended for severe AAC. Research has 


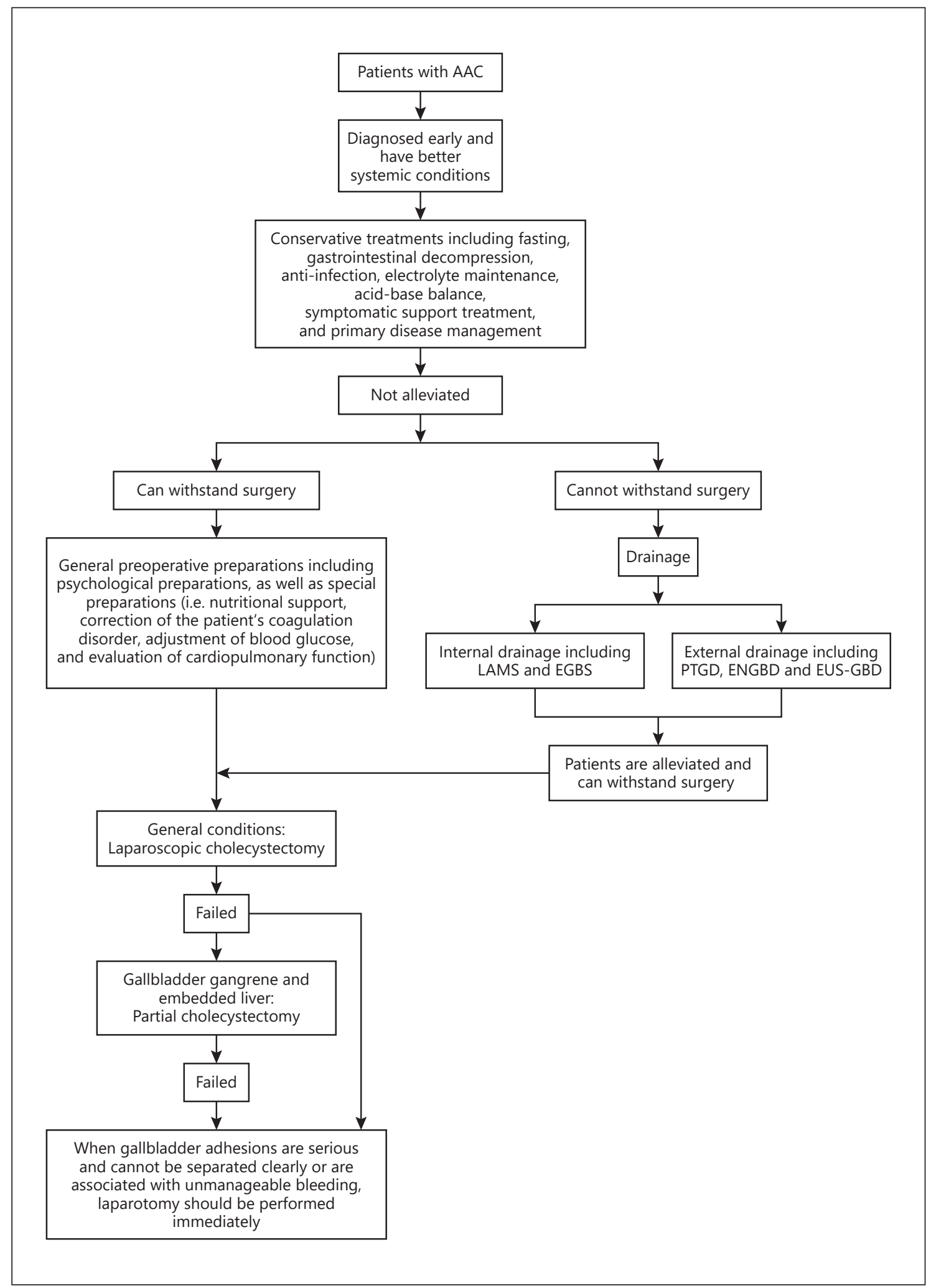

Fig. 5. A therapeutic algorithm of AAC. AAC, acute acalculous cholecystitis; LAMS, lumen-apposing fully covered metal stent; EGBS, endoscopic gallbladder stenting; PTGD, percutaneous transhepatic gallbladder drainage; ENGBD, endoscopic naso-gallbladder drainage; EUS-GBD, endoscopic ultrasound-guided gallbladder drainage. 
Fig. 6. A laparoscopic image was taken during treatment for AAC. Severe inflammation of the full gallbladder and adhesion to surrounding tissues can be seen. AAC, acute acalculous cholecystitis.
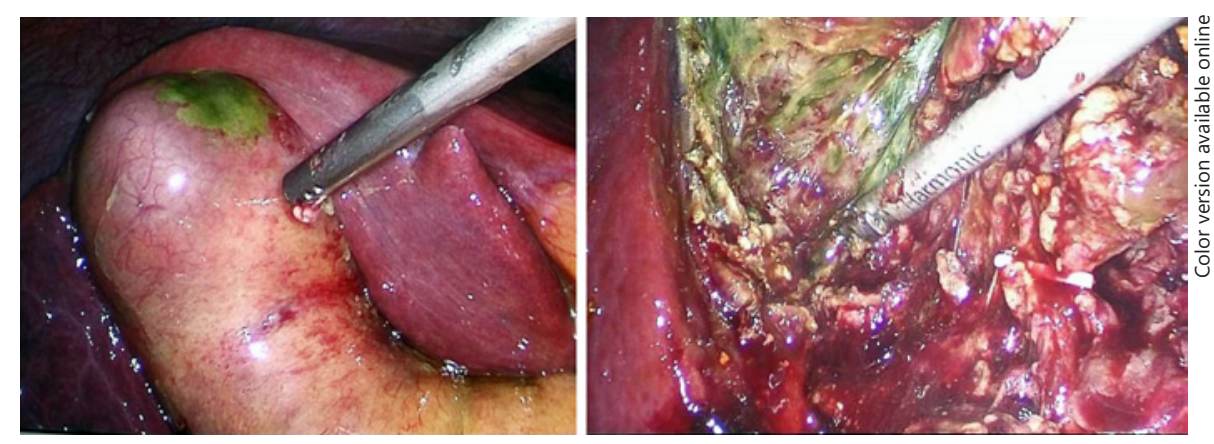

shown that the incidence of gangrenous cholecystitis is higher in AAC patients [51-53]. However, early surgical treatment is recommended for patients with ACC. Early studies have shown that the postoperative mortality rate in AAC ranges from $9 \%$ to $75 \%$, significantly higher than that in calculous cholecystitis. The mortality rate varies depending on the underlying disease and is more likely to be due to concurrent organ system lesions than hepatobiliary complications [54]. Chung et al. [55] conducted a retrospective study on 57 patients with AAC. Symptoms resolved within 4 days in 53 of the 57 (93\%) patients. The inhospital mortality rate was $21 \%(11 / 57)$ and elective cholecystectomy was performed in 18/57 (31\%). Twentyeight patients were managed nonoperatively, and cholecystostomy tubes were subsequently removed. These 28 patients were followed up over a median of 32 months, and recurrent cholecystitis occurred in 2 (7\%) [55]. A therapeutic algorithm of AAC can be seen in Figure 5.

\section{Conservative Treatment}

For patients who are diagnosed early, with better systemic conditions and a mild stage of the illness, conservative treatments, including fasting, gastrointestinal decompression, anti-infection, electrolyte maintenance, acid-base balance, symptomatic support treatment, and primary disease management, are initially attempted [52]. When selecting an antibiotic treatment, it is important to dynamically review the blood routine, biochemical factors, infection, and other laboratory indicators and closely monitor the patient's vital signs and overall condition. Because biliary tract infections are mainly caused by Gram-negative bacteria, third-generation cephalosporins and aminoglycosides are commonly used. If conservative treatment does not alleviate or even aggravate, the patient's condition, decisive surgical treatment should be performed to minimize the risk for gallbladder gangrene and perforation.

A Review of Acute Acalculous Cholecystitis

\section{Cholecystectomy}

Previous studies have shown that the preferred treatment for AAC patients is cholecystectomy, to minimize trauma, which may be laparoscopic, open, or partial cholecystectomy. Before surgery, general preparations should be made, including psychological preparations, nutritional support, correction of the patient's coagulation disorder, adjustment of blood glucose, and evaluation of cardiopulmonary function [49]. During the operation, the surgeon should systematically, gently, and carefully separate the adhesive tissues, to prevent damage to important blood vessels and nerves. If any gallbladder adhesions are serious and cannot be separated clearly, or are associated with uncontrollable bleeding, laparotomy should be performed immediately. Gallbladder gangrene and embedded liver make liver excision difficult; in a case where these conditions are present, partial cholecystectomy is feasible. At the same time, the mucous membrane of the remaining gallbladder is scratched, and chemical treatment is provided, to prevent biliary peritonitis. The color, quantity, and character of the drained fluid should be observed and recorded. According to the 2018 Tokyo Guidelines, the surgical technique should be selected based on the surgical risk. There are many safety benefits of laparoscopy, including less painful incision sites, shorter hospital stays, shorter recovery periods, and improved quality of life [49]. Figure 6 shows an intraoperative image.

\section{Drainage}

For patients in critical condition who cannot tolerate anesthesia and surgery, ultrasound-guided PC is an option. A PC catheter is placed through the liver (also known as percutaneous transhepatic gallbladder drainage [PTGD]) and the abdomen. Placing a PC catheter through the abdomen can easily cause bile leakage, and the formation of the fibrous sinus tract is relatively late, compared to PTGD. Thus, PTGD is generally the first choice in clin- 
Fig. 7. Endoscopic transpapillary drainage of the gallbladder in acute cholecystitis. a The guidewire is advanced into the gallbladder. b A $5 \mathrm{~F}$ naso-gallbladder tube is placed in the gallbladder. c A 7F doublepigtail plastic stent is placed in the gallbladder.
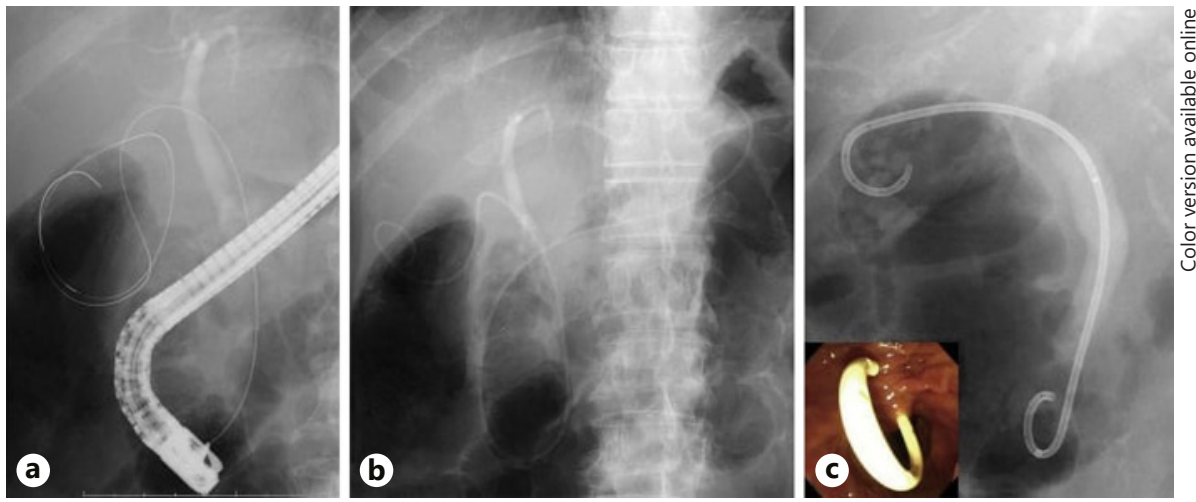

ical practice [56-58]. PC for the treatment of AAC has the following advantages: (1) it can quickly relieve the pressure in the gallbladder, with favorable effects on drainage and a decline in inflammation, (2) it is associated with less trauma and less anesthetic complications compared to surgery, (3) it has a short operation time, quick recovery, and a low incidence of postoperative complications, and (4) it can be used as a single treatment. PTGD is a safe and effective treatment method with clear efficacy, a simple operating procedure, and fewer complications, especially for elderly patients [56]. After placing the PC tube, the color, drainage, and bile characteristics should be monitored, to prevent prolapse and contortion of the PC tube, and to evaluate liver function, especially to determine the presence of cholestasis. However, there is still controversy regarding the removal of the $\mathrm{PC}$ tube. Based on a study on 90 AAC patients, Balmadrid et al. [59] concluded that the PC tube should be removed, if gallbladder angiography (which was performed after 1 week, when symptoms and laboratory results improved) revealed a smooth bile duct and smooth entrance of the contrast agent into the duodenum. Noh et al. [51] treated 271 patients with AAC with PC. After placing the PC tube for 4 days, 235 patients $(86.7 \%)$ had improved symptoms and laboratory results. Only 6 patients (2\%) had complications. Recently, endoscopic transpapillary gallbladder drainage under ERCP (involving endoscopic naso-gallbladder drainage and gallbladder stenting [EGBS] and endoscopic ultrasoundguided gallbladder drainage [EUS-GBD]) has been reported as novel effective alternative gallbladder drainage procedures in patients with AAC [60]. LAMS is placed between the duodenal bulb or the gastric antrum and the gallbladder during an endoscopic ultrasound. The 2 sides of the stent are fixed to the gastrointestinal tract and the gallbladder, respectively, to establish a safe passage for internal drainage. It is suitable for patients with gallblad- der enlargement, who are difficult to treat with direct surgical resection, and those who may easily develop duodenal or gastric perforation. It can also be used as a palliative care for patients who cannot tolerate surgery or those who have a short life expectancy [59]. A multicenter retrospective study showed that LAMS is feasible in clinical settings and is associated with lower pain scores, shorter hospital stays, and fewer repeated interventions, when compared with PC [61]. Jain et al. [62] analyzed 189 patients undergoing endoscopic ultrasound-guided LAMS and reported that the incidence of stent displacement was only $1.1 \%$. Therefore, LAMS is an effective treatment for AAC that is also accepted in the 2018 Tokyo Guidelines [60]. Wire-guided cannulation, with a sphincterotome for selective bile duct cannulation, has been reported to have a higher success rate and lower incidence of postERCP pancreatitis [63]. Figure 7 shows a typical image from biliary drainage.

\section{Conclusion}

The pathogenesis of AAC is complex, including abnormal anatomical structure of the biliary tract system, cholestasis, gallbladder ischemia-reperfusion injury, bacterial infections, and other risk factors. AAC must be diagnosed early and accurately so that the primary disease can be actively controlled, and symptomatic support treatments can be given. The most effective surgical strategies are reported in the 2018 Tokyo Guidelines. Drainage techniques, such as PTGBD, endoscopic transpapillary gallbladder drainage, endoscopic naso-gallbladder drainage, endoscopic gallbladder stenting, endoscopic ultrasound-guided gallbladder drainage, and wire-guided cannulation with a sphincterotome for selective bile duct cannulation, are effective strategies for severe AAC. 
Each of these techniques has advantages and disadvantages, which should be considered on a case-to-case basis. This article has comprehensively summarized the latest progress in AAC research, and our report can help clinicians strengthen their understanding of AAC, achieve early diagnosis, and rapidly select the most effective treatment, which will play a role in AAC research in the future.

\section{Conflict of Interest Statement}

The authors declare no conflict of interest.

\section{Funding Sources}

This study was funded by 345 Talent Project, Shenyang Science Technology Innovation Talent Support Program for Youth and Midlife (RC200121).

\section{Author Contributions}

Y.F. contributed to design of the work and manuscript preparation. L.P. contributed to data acquisition and analysis. W.D. contributed to data acquisition and analysis. S.W. contributed to data acquisition and analysis. J.K. contributed to manuscript final version approval.

\section{References}

1 Kimura Y, Takada T, Kawarada Y, Nimura Y, Hirata $K$, Sekimoto $M$, et al. Definitions, pathophysiology, and epidemiology of acute cholangitis and cholecystitis: Tokyo guidelines. J Hepatobiliary Pancreat Surg. 2007;14: $15-26$.

2 Huffman JL, Schenker S. Acute acalculous cholecystitis: a review. Clin Gastroenterol Hepatol. 2010;8:15-22.

3 Laurila JJ, Ala-Kokko TI, Laurila PA, Saarnio J, Koivukangas V, Syrjälä H, et al. Histopathology of acute acalculous cholecystitis in critically ill patients. Histopathology. 2005;47: 485-92.

4 Poddighe D, Sazonov V. Acute acalculous cholecystitis in children. World J Gastroenterol. 2018;24:4870-9.

5 Treinen C, Lomelin D, Krause C, Goede M, Oleynikov D. Acute acalculous cholecystitis in the critically ill: risk factors and surgical strategies. Langenbecks Arch Surg. 2015;400: 421-7.

6 Kullmann T, Issekutz Á, Oláh A, Rácz I. [Acute acalculous cholecystitis: from common to rare causes]. Orv Hetil. 2014;155:89-91.

7 Orlando R, Gleason E, Drezner AD. Acute acalculous cholecystitis in the critically ill patient. Am J Surg. 1983;145:472-6.

8 Taoka H. Experimental study on the pathogenesis of acute acalculous cholecystitis, with special reference to the roles of microcirculatory disturbances, free radicals and membrane-bound phospholipase A2. Gastroenterol Jpn. 1991;26:633-44.

9 Hakala T, Nuutinen PJ, Ruokonen ET, Alhava E. Microangiopathy in acute acalculous cholecystitis. Br J Surg. 1997;84:1249-52.

10 Vakkala M, Laurila JJ, Saarnio J, Koivukangas V, Syrjälä H, Karttunen T, et al. Cellular turnover and expression of hypoxic-inducible factor in acute acalculous and calculous cholecystitis. Crit Care. 2007;11:R116.

11 Tana M, Tana C, Cocco G, Iannetti G, Romano M, Schiavone C. Acute acalculous cholecystitis and cardiovascular disease: a land of confusion. J Ultrasound. 2015;18:317-20.
12 Treinen C, Lomelin D, Krause C, Goede M, Oleynikov D. Acute acalculous cholecystitis in the critically ill: risk factors and surgical strategies. Langenbecks Arch Surg. 2015;400: 421-7.

13 Walsh K, Goutos I, Dheansa B. Acute acalculous cholecystitis in burns: a review. J Burn Care Res. 2018;39:724-8.

14 Croteau D, Flowers C, Kulick CG, Brinker A, Kortepeter CM. Acute acalculous cholecystitis: a new safety risk for patients with MS treated with alemtuzumab. Neurology. 2018; 90:e1548-52.

15 da Fonseca LG, Barroso-Sousa R, Sabbaga J, Hoff PM. Acute acalculous cholecystitis in a patient with metastatic renal cell carcinoma treated with sunitinib. Clin Pract. 2014;4:635.

16 Porter JB, Jick H, Dinan BJ. Acute cholecystitis and thiazides. N Engl J Med. 1981;304: 954-5.

17 Fujioka K, Nishimura T, Seki M, Kinoshita M, Mishima N, Irimajiri S, et al. Genotype 1 hepatitis $\mathrm{E}$ virus infection with acute acalculous cholecystitis as an extrahepatic symptom: a case report. Trop Med Health. 2016;44:18.

18 Teshale EH, Hu DJ, Holmberg SD. The two faces of hepatitis E virus. Clin Infect Dis. 2010; 51:328-34.

19 Araki H, Shimizu S, Hayashi K, Yamada T, Kusakabe A, Kanie H, et al. Acute acalculous cholecystitis caused by Giardia lamblia. Intern Med. 2017;56:1657-62.

20 Lee GY, Poovorawan K, Intharasongkroh D, Sa-Nguanmoo P, Vongpunsawad S, Chirathaworn $\mathrm{C}$, et al. Hepatitis $\mathrm{E}$ virus infection: epidemiology and treatment implications. World J Virol. 2015;4:343-55.

21 Young C, Lampe R. Primary Epstein-Barr virus infection in an adolescent female complicated by acute acalculous cholecystitis. Cureus. 2019;11:e5044.

22 Simões AS, Marinhas A, Coelho P, Ferreira S. Acalculous acute cholecystitis during the course of an enteroviral infection. BMJ Case Rep. 2019;12:e228306.
23 Barie PS, Eachempati SR. Acute acalculous cholecystitis. Gastroenterol Clin North Am. 2010;39:343-57, x.

24 Iqbal S, Khajinoori M, Mooney B. A case report of acalculous cholecystitis due to Salmonella paratyphi B. Radiol Case Rep. 2018;13: 1116-8.

25 Poddighe D, Tresoldi M, Licari A, Marseglia GL. Acalculous acute cholecystitis in previously healthy children: general overview and analysis of pediatric infectious cases. Int J Hepatol. 2015;2015:459608.

26 Hariz A, Beji I, Hamdi MS, Cherif E. Brucellosis, an uncommon cause of acute acalculous cholecystitis: two new cases and concise review. BMJ Case Rep. 2019;12:e229616.

27 Szvalb AD, Kontoyiannis DP. Acute acalculous cholecystitis due to Fusarium species and review of the literature on fungal cholecystitis. Mycoses. 2019;62:847-53.

28 Castelijn DAR, Wattel-Louis GH. An acute acalculous cholecystitis in a returned travel couple. PLoS Negl Trop Dis. 2018;12: e0006177.

29 Mahapatra R, Cohen D, Viccellio AW, Sasson A, Bandovic J, Spitzer ED, et al. Acute acalculous cholecystitis as a manifestation of ehrlichiosis. Ticks Tick Borne Dis. 2019;10: 1033-4.

30 Du M, Suo J, Liu B, Xing Y, Chen L, Liu Y. Post-ERCP infection and its epidemiological and clinical characteristics in a large Chinese tertiary hospital: a 4-year surveillance study. Antimicrob Resist Infect Control. 2017;6:131.

31 Chen Y, Kong J, Wu S. Cholesterol gallstone disease: focusing on the role of gallbladder. Lab Invest. 2015;95:124-31.

32 Xiao ZL, Rho AK, Biancani P, Behar J. Effects of bile acids on the muscle functions of guinea pig gallbladder. Am J Physiol Gastrointest Liver Physiol. 2002;283:G87-94.

33 Huang Y, Mei F, Yu B, Zhang H-J, Han J, Jiang $\mathrm{Z}-\mathrm{Y}$, et al. Distribution of the interstitial Cajal-like cells in the gallbladder and extrahepatic biliary duct of the guinea-pig. Acta Histochem. 2009;111:157-65. 
34 Falk V, Low G, Bigam D, Sandha G. Acute acalculous cholecystitis of an intrahepatic gallbladder causing Mirizzi's syndrome. BMJ Case Rep. 2018:2018:bcr2018224365.

35 Owen CC, Jain R. Acute acalculous cholecystitis. Curr Treat Options Gastro. 2005;8(2): 99-104.

36 Shin SJ, Na KS, Jung SS, Bae SC, Yoo DH, Kim SY, et al. Acute acalculous cholecystitis associated with systemic lupus erythematosus with Sjogren's syndrome. Korean J Intern Med. 2002;17:61-4.

37 Otsuka Y, Inoue Y. So-called acute acalculous cholecystitis in macrophage activation syndrome. Intern Med. 2016;55:3043-6.

38 Thampy R, Khan A, Zaki IH, Wei W, Korivi BR, Staerkel G, et al. Acute acalculous cholecystitis in hospitalized patients with hematologic malignancies and prognostic importance of gallbladder ultrasound findings. J Ultrasound Med. 2019;38:51-61.

39 Kuroi Y, Imazato D, Yamazaki K, Kasuya H. Acute cholecystitis in patients with stroke. Neurol India. 2019;67:439-41.

40 Yasuda H, Takada T, Kawarada Y, Nimura Y, Hirata K, Kimura Y, et al. Unusual cases of acute cholecystitis and cholangitis: Tokyo guidelines. J Hepatobiliary Pancreat Surg. 2007;14:98-113.

41 Gouma DJ, Oberto H. Acute calculous cholecystitis. What is new in diagnosis and therapy? HPB Surg. 1992;6:69-78.

42 Chen X, Tang S, Yu D, Liu Z. Logistic regression analysis of gallbladder lesions of $\geq 1 \mathrm{~cm}$ in diameter diagnosed by ultrasound. Chin J Med Imaging. 2013;12:447-50.

43 Chawla A, Bosco JI, Lim TC, Srinivasan S, Teh HS, Shenoy JN. Imaging of acute cholecystitis and cholecystitis-associated complications in the emergency setting. Singapore Med J. 2015; 56:438-44; quiz 444.

44 Yeo DM, Jung SE. Differentiation of acute cholecystitis from chronic cholecystitis: determination of useful multidetector computed tomography findings. Medicine. 2018;97: e11851.

45 Shafiq M, Zafar Y. Acute acalculous cholecystitis in the setting of negative ultrasound and computed tomography scan of the abdomen. Cureus. 2018;10:e2243.

46 Shiryajev YN, Glebova AV, Koryakina TV, Kokhanenko NY. Acute acalculous cholecystitis complicated by MRCP-confirmed Mirizzi syndrome: a case report. Int J Surg Case Rep. 2012;3:193-5.

47 Hassan IM, Que L, Rutland M. The role of glyceryl trinitrate (GTN) in $99 \mathrm{~m}$ Tc-HIDA with morphine provocation scan for the investigation of type III sphincter of oddi dysfunction (SOD). J Nucl Med. 2016;57(Suppl 2):646.

48 Adachi T, Eguchi S, Muto Y. Pathophysiology and pathology of acute cholecystitis: a secondary publication of the Japanese version from 1992. J Hepatobiliary Pancreat Sci. 2021. Epub ahead of print.

49 Okamoto K, Suzuki K, Takada T, Strasberg SM, Asbun HJ, Endo I, et al. Tokyo guidelines 2018: flowchart for the management of acute cholecystitis. J Hepatobiliary Pancreat Sci. 2018;25:55-72.

50 Yokoe M, Hata J, Takada T, Strasberg SM, Asbun HJ, Wakabayashi G, et al. Tokyo guidelines 2018: diagnostic criteria and severity grading of acute cholecystitis (with videos). J Hepatobiliary Pancreat Sci. 2018;25:41-54.

51 Noh SY, Gwon DI, Ko GY, Yoon HK, Sung $\mathrm{KB}$. Role of percutaneous cholecystostomy for acute acalculous cholecystitis: clinical outcomes of 271 patients. Eur Radiol. 2018;28: 1449-55.

52 Gu MG, Kim TN, Song J, Nam YJ, Lee JY, Park JS. Risk factors and therapeutic outcomes of acute acalculous cholecystitis. Digestion. 2014;90:75-80.

53 Real-Noval H, Fernández-Fernández J, SolerDorda G. Predicting factors for the diagnosis of gangrene acute cholecystitis. Cir Cir. 2019; 87:443-9.

54 Shapiro MJ, Luchtefeld WB, Kurzweil S, Kaminski DL, Durham RM, Mazuski JE. Acute acalculous cholecystitis in the critically ill. Am Surg. 1994;60:335-9.

55 Chung YH, Ryoung Choi E, Kim KM, Kim MJ, Lee JK, Lee KT, et al. Can percutaneous cholecystostomy be a definitive management for acute acalculous cholecystitis? J Clin Gastroenterol 2012;46:216-9.

$56 \mathrm{Li} \mathrm{Y,} \mathrm{Liu} \mathrm{H,} \mathrm{Li} \mathrm{W.} \mathrm{Feasibility} \mathrm{and} \mathrm{efficacy} \mathrm{of}$ ultrasound-guided percutaneous transhepatic cholecystectomy and drainage in the treatment of acute noncalculous cholecystitis in the elderly. J Clin Gastroenterol. 2015;27: 141-3.

57 Morales-Maza J, Rodríguez-Quintero JH, Santes O, Hernández-Villegas AC, ClementeGutiérrez U, Sánchez-Morales GE, et al. Percutaneous cholecystostomy as treatment for acute cholecystitis: what has happened over the last five years? A literature review. Rev Gastroenterol Mex. 2019;84:482-91.

58 Dvorak P, Hoffmann P, Renc O, Dusek T, Rejchrt S, Slezak O, et al. Percutaneous cholecystostomy in the management of acute cholecystitis - 10 years of experience. Wideochir Inne Tech Maloinwazyjne. 2019; 14:516-25.

59 Balmadrid B. Recent advances in management of acalculous cholecystitis. F1000Res. 2018;7:1660.

60 Mori Y, Itoi T, Baron TH, Takada T, Strasberg SM, Pitt HA, et al. Tokyo guidelines 2018: management strategies for gallbladder drainage in patients with acute cholecystitis (with videos). J Hepatobiliary Pancreat Sci. 2018;25: 87-95.

61 Irani S, Ngamruengphong S, Teoh A, Will U, Nieto J, Abu Dayyeh BK, et al. Similar efficacies of endoscopic ultrasound gallbladder drainage with a lumen-apposing metal stent versus percutaneous transhepatic gallbladder drainage for acute cholecystitis. Clin Gastroenterol Hepatol. 2017;15:738-45.

62 Jain D, Bhandari BS, Agrawal N, Singhal S. Endoscopic ultrasound-guided gallbladder drainage using a lumen-apposing metal stent for acute cholecystitis: a systematic review. Clin Endosc. 2018;51:450-62.

63 Kawakami H, Maguchi H, Mukai T, Hayashi $\mathrm{T}$, Sasaki $\mathrm{T}$, Isayama $\mathrm{H}$, et al. A multicenter, prospective, randomized study of selective bile duct cannulation performed by multiple endoscopists: the BIDMEN study. Gastrointest Endosc. 2012;75:362-72.e1. 